\title{
The role of everolimus in liver transplantation
}

This article was published in the following Dove Press journal:

Clinical and Experimental Gastroenterology

2 September 2014

Number of times this article has been viewed

\author{
Rainer Ganschow' \\ Jörg-Matthias Pollok ${ }^{2}$ \\ Martin Jankofsky ${ }^{3}$ \\ Guido Junge ${ }^{4}$ \\ 'Department of Pediatrics, \\ ${ }^{2}$ Department of General, Visceral, \\ Thoracic, and Vascular Surgery, \\ ${ }^{3}$ Department of Pediatrics, University \\ of Bonn, Bonn, Germany; ${ }^{4}$ Integrated \\ Hospital Care, Novartis Pharma AG, \\ Basel, Switzerland
}

\begin{abstract}
During the last 5 decades, liver transplantation has witnessed rapid development in terms of both technical and pharmacologic advances. Since their discovery, calcineurin inhibitors (CNIs) have remained the standard of care for immunosuppression therapy in liver transplantation, improving both patient and graft survival. However, adverse events, particularly posttransplant nephrotoxicity, associated with long-term CNI use have necessitated the development of alternate treatment approaches. These include combination therapy with a CNI and the inosine monophosphate dehydrogenase inhibitor mycophenolic acid and use of mammalian target of rapamycin (mTOR) inhibitors. Everolimus, a 40-O-(2-hydroxyethyl) derivative of mTOR inhibitor sirolimus, has a distinct pharmacokinetic profile. Several studies have assessed the role of everolimus in liver transplant recipients in combination with CNI reduction or as a CNI withdrawal strategy. The efficacy of everolimus-based immunosuppressive therapy has been demonstrated in both de novo and maintenance liver transplant recipients. A pivotal study in 719 de novo liver transplant recipients formed the basis of the recent approval of everolimus in combination with steroids and reduced-dose tacrolimus in liver transplantation. In this study, everolimus introduced at 30 days posttransplantation in combination with reduced-dose tacrolimus (exposure reduced by 39\%) showed comparable efficacy (composite efficacy failure rate of treated biopsy-proven acute rejection, graft loss, or death) and achieved superior renal function as early as month 1 and maintained it over 2 years versus standard exposure tacrolimus. This review provides an overview of the efficacy and safety of everolimus-based regimens in liver transplantation in the de novo and maintenance settings, as well as in special populations such as patients with hepatocellular carcinoma recurrence, hepatitis $C$ virus-positive patients, and pediatric transplant recipients. We also provide an overview of ongoing studies and discuss potential expansion of the role for everolimus in these settings.
\end{abstract}

Keywords: mTOR inhibitors, everolimus, liver transplantation, efficacy, safety

\section{Introduction to liver transplantation}

During the 5 decades since the first human liver transplant in $1963,{ }^{1}$ there have been a number of important technical and pharmacological advances in liver transplantation. Early results were poor, with a survival of only 13 months, ${ }^{2,3}$ but they started to improve after the introduction of more-effective immunosuppressive agents. Today, better recipient selection (based on Model for End-Stage Liver Disease score ${ }^{4}$ and Milan criteria) $)^{5,6}$ and evolving surgical techniques and perioperative management have resulted in improved short-term outcomes. Surgical advances include reduced-sized liver grafts in $1981,{ }^{7}$ followed by split liver transplantation in $1988^{8}$ and the use of living donors in the 1990s. ${ }^{9,10}$ Indications for liver transplantation have also changed over time. In addition to the common indications, including acute and chronic conditions such as
Correspondence: Rainer Ganschow

Department of Pediatrics,

University of Bonn, Bonn, Germany

Tel +49228 28733213

Fax +492282873 3325

Email rainer.ganschow@ukb.uni-bonn.de 
chronic viral hepatitis $\mathrm{C}$, hepatitis $\mathrm{B}$, autoimmune conditions (primary biliary cirrhosis, primary sclerosing cholangitis, autoimmune hepatitis), and hepatic malignancies, patients with metabolic conditions such as nonalcoholic steatohepatitis are now more frequently being wait-listed for liver transplantation. ${ }^{11}$

Immunosuppression after liver transplantation in the 1960s and 1970s mainly included use of chemical agents such as purine analog azathioprine and steroids. With this regimen, 1 - and 5-year survival rates were $32.9 \%$ and $20.0 \%$, respectively. ${ }^{12}$ The introduction of cyclosporine in the early 1980s significantly improved both graft and patient survival, ${ }^{12,13}$ with a cyclosporine-based regimen achieving 1 - and 5-year survival rates of $69.7 \%$ and $62.8 \%$, respectively. ${ }^{12}$

Despite the technological and pharmacological advances and improvement in short-term outcomes, management issues associated with surgery, immunosuppression, and recurrence of disease still remain a challenge in liver transplantation. Although the incidence of acute rejection has declined over the years as immunosuppressive regimens have developed, other complications associated with the surgical procedure or immunosuppression, such as hepatic artery thrombosis (HAT), biliary tract complications, and infections, ${ }^{14,15}$ are of concern. Potential problems related to chronic immunosuppression include systemic events (pulmonary, renal, or neurological) and malignancy. ${ }^{14}$ In addition, recurrence of original diseases such as hepatitis $\mathrm{C}$ virus (HCV) infection, hepatocellular carcinoma (HCC), and primary sclerosing cholangitis represents a major clinical obstacle. Recurrent $\mathrm{HCV}$ infection after liver transplantation is universal and is associated with accelerated liver fibrogenesis, leading to allograft cirrhosis in at least $30 \%$ of patients within 5 years of transplantation. ${ }^{16,17}$ Posttransplant HCC recurrence has been reported in up to $20 \%$ of patients; ${ }^{18}$ although lower incidence $(<10 \%)$ has been reported among the patients within the Milan criteria. ${ }^{19,20}$ Recurrence of primary sclerosing cholangitis has been reported in 10\%-38.7\% of liver transplant recipients. ${ }^{21}$

\section{Role of immunosuppression in liver transplantation}

At this time, the goal of immunosuppression in liver transplantation is to maintain graft function with a low rate of acute rejection while minimizing drug-related adverse effects. Under-immunosuppression can lead to an increased risk for graft rejection, whereas over-immunosuppression is associated with an increased risk for adverse events; notably, infections and malignancies. Thus, providing optimal immunosuppression is key. Calcineurin inhibitors (CNIs) represent the mainstay of immunosuppressive therapy in liver transplantation. With the introduction of CNI therapy, acute rejection rates have declined considerably. However, prolonged CNI exposure is associated with nephrotoxicity, ${ }^{22,23}$ neurotoxicity, ${ }^{24-26}$ increased risk for malignancies, ${ }^{27-29}$ metabolic complications, ${ }^{30,31}$ and hypertension. ${ }^{32}$

CNI-induced nephrotoxicity is the leading cause of renal dysfunction after liver transplantation ${ }^{22,23,33}$ and has been associated with significant morbidity and mortality. ${ }^{22,23}$ Incidence rates as high as $18.1 \%$ by 5 years posttransplant have been observed, ${ }^{23}$ and in the Model for End-Stage Liver Disease era, the 5-year cumulative incidence of chronic renal failure has been reported to be $22 \% .{ }^{34}$ Such high rates of nephrotoxicity, along with steroid-induced growth retardation, can have a major effect, particularly in pediatric recipients, ${ }^{35-37}$ who have a longer exposure to immunosuppressive therapy. Indeed, renal dysfunction has been reported in as many as $32 \%$ of pediatric liver transplant recipients at an average follow-up of 7.6 years after transplantation. ${ }^{38}$ In addition, CNI-induced neurological adverse effects have been reported in up to $40 \%$ of patients receiving cyclosporine. ${ }^{25}$ Both cyclosporine and tacrolimus are associated with an increased risk for HCC recurrence in liver transplant recipients. ${ }^{39,40}$ Metabolic adverse events, such as hyperlipidemia and new-onset diabetes mellitus (NODM), are also common with $\mathrm{CNIs},{ }^{30}$ although the incidence rates vary; for example, a significantly higher incidence of NODM has been reported with tacrolimus than with cyclosporine. ${ }^{31}$

Delaying the introduction of CNIs or reducing CNI exposure are the strategies that have been explored to lower the adverse events associated with this class of drug. One approach in adult recipients has been to administer short-term induction therapy (polyclonal or monoclonal antibodies, or interleukin 2 receptor antibodies such as basiliximab) with delayed introduction of CNIs. ${ }^{41-44}$ Use of induction therapy is also known to reduce the rates of acute rejection in children receiving CNI-based immunosuppression. ${ }^{45-48}$

Other treatment strategies focus on optimizing immune modulation by combining immunosuppressants with different mechanisms of action to minimize the adverse events while maintaining immunosuppressive efficacy. ${ }^{49}$ Maintenance immunosuppression in liver transplant recipients typically includes combinations of drugs that target complementary pathways, most frequently a CNI plus an inosine monophosphate dehydrogenase inhibitor, with or without steroids. ${ }^{50}$ 
Unlike the wide array of immunosuppressants approved for use in kidney transplantation, until recently, only the CNIs cyclosporine and tacrolimus, as well as mycophenolate mofetil, were approved for liver transplantation; moreover, cyclosporine plus mycophenolate mofetil was the only combination regimen approved in this setting. ${ }^{51-53}$ Development of the mammalian target of rapamycin (mTOR) inhibitors everolimus and sirolimus generated considerable interest among transplant physicians, especially in view of their potential to reduce or eliminate CNIs. The mTOR inhibitors exert their immunosuppressive effect via a separate mechanism and exhibit a different pharmacological profile to CNIs and inosine monophosphate dehydrogenase inhibitors, providing a new option in the immunosuppressive armamentarium for transplant recipients. Of the two mTOR inhibitors, sirolimus was introduced first in the late 1990s for prophylaxis of rejection in solid organ transplantation. Everolimus is a 40-O-(2-hydroxyethyl) derivative, ${ }^{54}$ which was developed to improve the pharmacokinetic profile of sirolimus. The hydroxyethyl group provides a pharmacokinetic advantage, conferring faster absorption and a shorter half-life than sirolimus. ${ }^{55-57}$ Unlike sirolimus, no loading dose is required for everolimus, and the twice-daily dosing schedule allows better dose adjustments. ${ }^{57}$

Everolimus (in combination with cyclosporine and corticosteroids) was first approved in 2003 for the prophylaxis of organ rejection in kidney and heart transplant recipients in many European countries, followed by a US Food and Drug Administration (FDA) approval for kidney transplantation in 2010. Everolimus, in combination with reduced-dose tacrolimus and steroids, is the first approval by US FDA for an immunosuppressive agent in liver transplantation for more than a decade ${ }^{58}$ Of note, sirolimus is not approved for use in liver transplantation and carries a black box warning from the US FDA because of a high incidence of HAT, graft loss, and death. ${ }^{59}$ The review focuses on the use of everolimus-based immunosuppression in liver transplantation.

\section{Everolimus}

\section{Mechanism of action}

At an intracellular level, everolimus binds to FKB12. The resulting complex blocks the activation of the TOR complex 1 complex, a cycle-specific kinase that activates p70 ribosomal S6 kinase (p70S6k). ${ }^{60,61}$ Inhibition of the mTOR pathway prevents progression of the cell cycle from G1 into the $\mathrm{S}$ phase, thus suppressing interleukin (IL)-driven T-cell differentiation. Inactivation of the p70S6k in lymphocytes results in selective inhibition of ribosomal protein synthesis, thereby deactivating the immune response. ${ }^{60,62}$ mTOR plays an important role in several physiological processes, such that inhibition by everolimus also leads to various downstream consequences via an effect on nonimmune cells such as vascular smooth muscle cells, tubular epithelial cells, and fibroblasts. Antiangiogenic activity of mTOR inhibitors has been associated with a decrease in vascular endothelial growth factor production. ${ }^{63-65}$ Anticancer effects are mediated via the phosphatidylinositol 3-kinase/AKT/mTOR pathway, ${ }^{66}$ and antifibrotic activity has been linked to the mTOR/p70S6k/ procollagen 1 pathway. ${ }^{67}$

Everolimus is metabolized in the gut and liver by CYP3A4; therefore, concomitant administration of other CYP3A inhibitors such as verapamil, ketoconazole, and erythromycin may lead to drug-drug interactions. ${ }^{68-70}$ Routine therapeutic drug monitoring is recommended to guide dose adjustments when everolimus is coadministered with other CYP3A inhibitors. ${ }^{71}$ Everolimus also has shown synergism with cyclosporine in terms of the immunosuppressive effect. ${ }^{56,72}$ Tacrolimus and cyclosporine differ significantly in their interaction when coadministered with everolimus. Lower doses of everolimus are needed when coadministered with cyclosporine (so that reducing the dose of cyclosporine may decrease everolimus concentrations), whereas tacrolimus has a minimal effect on everolimus blood levels. ${ }^{73}$

\section{Efficacy studies}

The efficacy of everolimus has been demonstrated in de novo and maintenance liver transplant recipients. ${ }^{74-79} \mathrm{~A}$ summary of key randomized controlled trials of everolimus in liver transplant recipients is presented in Table 1.

Phase 1 and dose-finding studies of everolimus in combination with standard-dose cyclosporine in de novo liver transplant recipients revealed that everolimus at a dose of $2-4 \mathrm{mg} /$ day was well-tolerated in this population. ${ }^{80,81}$

In maintenance liver transplant recipients, a feasibility study $(\mathrm{N}=40)$ showed that conversion from $\mathrm{CNI}$ to everolimus with or without antimetabolite therapy was feasible in $75 \%$ of patients. This study also found that the improvement in renal function after conversion to everolimus directly correlated with baseline creatinine clearance. ${ }^{75}$ A multicenter, retrospective study of maintenance liver transplant patients conducted at nine French centers demonstrated that 12 months after conversion to everolimus, more than $60 \%$ of patients were CNI-free, and that conversion was associated with a low risk for acute rejection. In addition, a significant improvement in renal function was observed: mean estimated glomerular filtration rate (eGFR) increased 


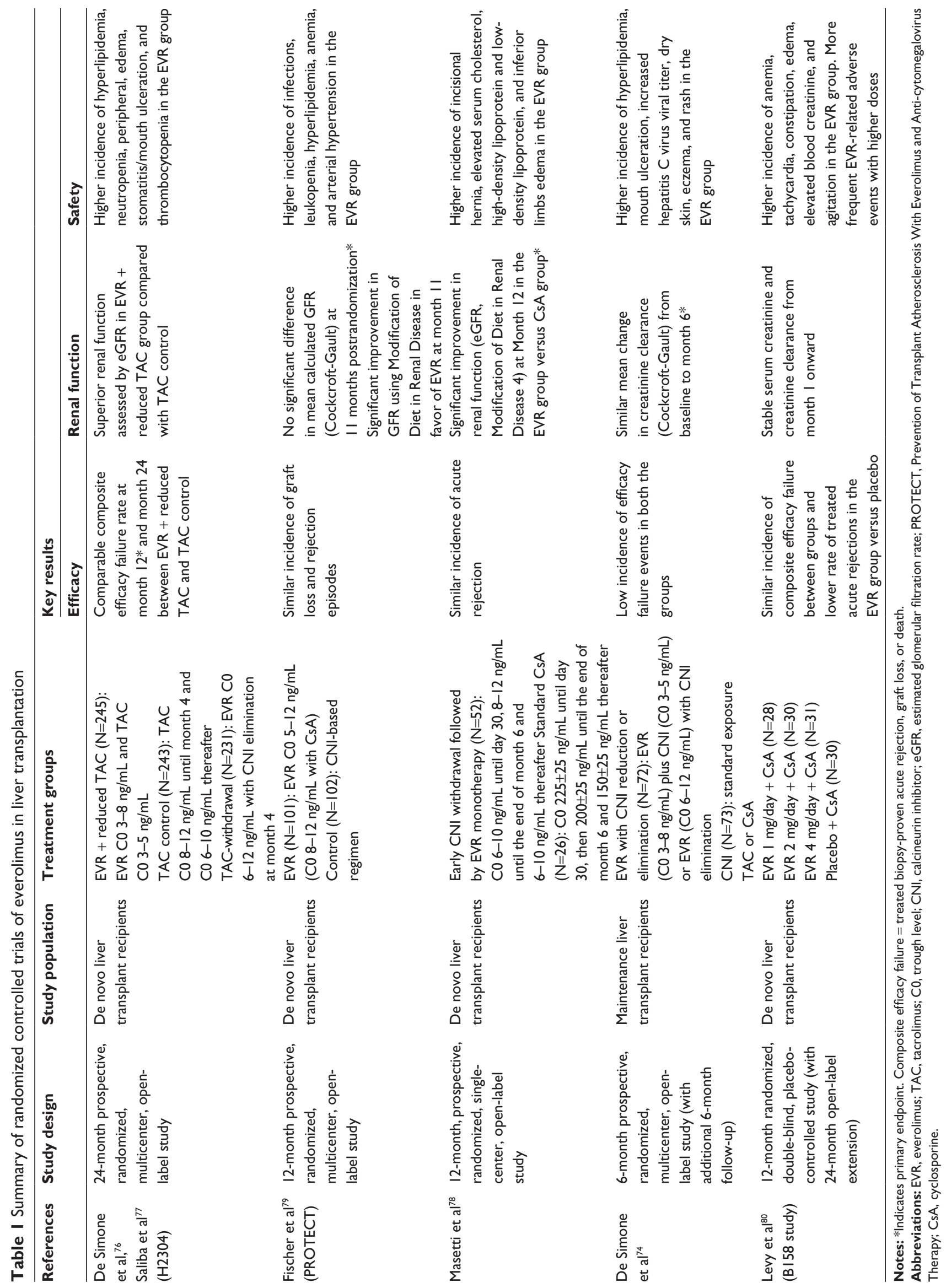


from $64.2 \pm 30 \mathrm{~mL} / \mathrm{minute}$ at day 0 to $68.4 \pm 32.5 \mathrm{~mL} /$ minute at month $12(P=0.007) .{ }^{82}$ In a randomized, open-label, multicenter study by De Simone et al, 145 maintenance liver transplant recipients (time since transplantation, $>3$ years) with CNI-related renal impairment were randomized either to start concentration-controlled everolimus with CNI reduction or discontinuation or to continue a standardexposure CNI regimen. ${ }^{74}$ Everolimus was compared with the standard-exposure CNI. Results showed that everolimus allows CNI withdrawal or reduction without compromising efficacy. CNI elimination was achieved in $80 \%$ and $85 \%$ of patients at 6 and 12 months, respectively, with a very low incidence of biopsy-proven acute rejection (BPAR). The incidence of BPAR was identical (1.4\%) at month 6 in both treatment groups and was $4.2 \%$ and $1.3 \%$ at month 12 in the everolimus and standard-exposure CNI groups, respectively. Despite safe conversion to everolimus without compromising efficacy, no significant improvement in renal function was observed. Low CNI exposure at baseline in both everolimus and standard-exposure CNI groups, higher CNI dose reductions in the control group, and the extended time since transplantation ( $>3$ years) were identified as the main contributing factors. The authors, therefore, hypothesized that earlier conversion to everolimus with subsequent CNI reduction may provide an increased benefit for renal function. $^{74}$

In de novo liver transplant recipients, Masetti et al described the use of everolimus in a single-center, randomized, phase 2 trial. $^{78}$ After treatment with cyclosporine for first 10 days, 78 liver transplant recipients were randomized either to receive everolimus plus cyclosporine for up to 30 days, followed by everolimus monotherapy, or to continue receiving cyclosporine with or without mycophenolate mofetil, depending on the presence of chronic kidney disease. Early withdrawal of cyclosporine with subsequent everolimus monotherapy was associated with a significant improvement in renal function (mean eGFR-Modification of Diet in Renal Disease [MDRD] $^{83}$ at month 12 was $87.7 \pm 26.1 \mathrm{~mL} /$ minute versus $59.9 \pm 12.6 \mathrm{~mL} /$ minute in the cyclosporine group; $P<0.001$ ). Furthermore, a higher proportion of patients had stage 3 or higher chronic kidney disease (eGFR $<60 \mathrm{~mL} /$ minute) in the cyclosporine group versus in the everolimus group (52.2\% versus $15.4 \% ; P=0.005)$. Comparable rates of BPAR $(5.7 \%$ versus $7.7 \%)$ were observed in both treatment groups (Figure 1). ${ }^{78}$

PROTECT, another study employing early conversion to everolimus, was a multicenter, open-label, randomized controlled trial in which 203 de novo liver transplant recipients

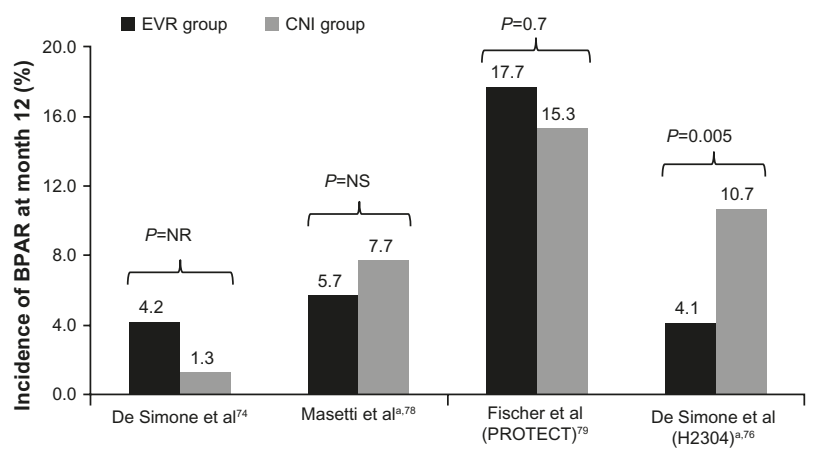

Figure I Incidence of biopsy-proven acute rejection at month 12 in comparative trials of everolimus.

Note: ${ }^{*}$ The $\mathrm{CNI}$ was cyclosporine in the study by Masetti et $\mathrm{a}^{78}$ and tacrolimus in the $\mathrm{H} 2304$ study.

Abbreviations: EVR, everolimus; CNI, calcineurin inhibitor; BPAR, biopsy-proven acute rejections; NR, not reported; NS, not significant.

were randomized at 30-60 days posttransplant to either continue a CNI-based regimen or start everolimus with CNI discontinuation. ${ }^{79}$ All patients received basiliximab induction, with or without maintenance corticosteroids. Results showed that conversion from a CNI-based to an everolimus-based regimen can be achieved safely, with beneficial effects on renal function. The incidences of a composite efficacy failure endpoint (BPAR, graft loss, death, or loss to follow-up; everolimus, $20.8 \%$, versus CNI, 20.4\%) and BPAR (everolimus, $17.7 \%$, versus CNI, 15.3\%) were similar between the two treatment groups. At month 11, GFR estimated using the Modification of Diet in Renal Disease formula (considered the appropriate formula for GFR calculation in liver transplant recipients) ${ }^{84}$ showed a significant difference between the everolimus and CNI groups (least square [LS] mean difference of $7.8 \mathrm{~mL} /$ minute in favor of everolimus; $P=0.021$ ). However, using the Cockroft-Gault formula, the mean difference in GFR between the everolimus and CNI groups $(2.9 \mathrm{~mL} /$ minute; $P=0.46)$ did not reach the protocoldefined superiority criterion (a between-group difference in GFR of $8 \mathrm{~mL} / \mathrm{minute}{ }^{79}$

In the pivotal registration study (H2304) that led to everolimus approval in liver transplantation, 719 de novo liver transplant recipients were randomized after a 30 \pm 5 -day run-in period to everolimus plus reduced tacrolimus, standard-exposure tacrolimus, or everolimus with tacrolimus elimination. Tacrolimus exposure was reduced by $39 \%$ in the everolimus plus reduced tacrolimus group compared with in the standard-exposure tacrolimus group. ${ }^{77}$ Everolimus with reduced tacrolimus proved to be noninferior to standardexposure tacrolimus, showing a numerically lower incidence rate of the primary endpoint of efficacy failure, defined as 
treated BPAR, graft loss, or death at month $12 .{ }^{76}$ The study also showed that immunosuppression with everolimus plus reduced tacrolimus was associated with significantly fewer BPAR episodes than standard-exposure tacrolimus (4.1\% versus $10.7 \% ; P=0.005$ at month 12 and $6.1 \%$ versus $13.3 \% ; P=0.010$ at month 24 ), and that BPAR was less severe. ${ }^{76,77}$ A high incidence of acute rejections led to premature termination of enrollment to the tacrolimus elimination group, in which tacrolimus was completely withdrawn by the end of month 4 after transplantation. Most of these acute rejections occurred around the time of tacrolimus elimination. Abrupt cessation of tacrolimus might have contributed to the high rate of acute rejections. The authors speculated that an mTOR inhibitor regimen without induction therapy and with no additional immunosuppressive comedication might not be a viable option until 90 days after liver transplantation. In terms of renal function, everolimus plus reduced tacrolimus was associated with superior renal function (eGFR [MDRD-4]) at 12 and 24 months compared with standard tacrolimus (Figure 2). The improvement in eGFR from randomization to month 24 was significantly higher in the everolimus plus reduced tacrolimus group versus in the standard tacrolimus group (mean difference, $6.7 \mathrm{~mL} /$ minute $/ 1.73 \mathrm{~m}^{2} ; 97.5 \%$ confidence interval, $\left.1.9-11.4 \mathrm{~mL} / \mathrm{minute} / 1.73 \mathrm{~m}^{2} ; P=0.002\right)$. For patients who continued their randomized treatment, the mean difference in eGFR was $11.5 \mathrm{~mL} /$ minute $/ 1.73 \mathrm{~m}^{2}$ in favor of

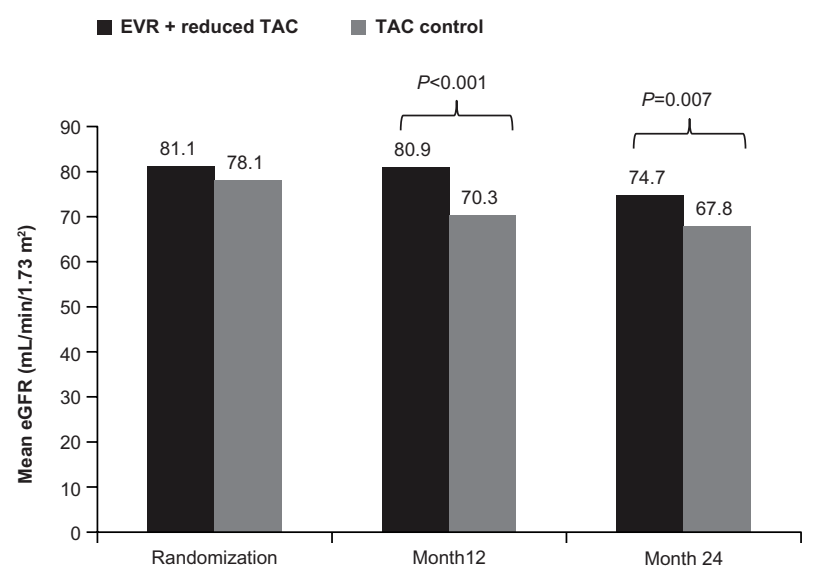

Figure 2 Mean estimated glomerular filtration rate with everolimus + reduced tacrolimus versus tacrolimus control in the $\mathrm{H} 2304$ study.

Note: Copyright (C) 2012 The American Society of Transplantation and the American Society of Transplant Surgeons. De Simone P, Nevens F, De Carlis L, et al; H2304 Study Group. Everolimus with reduced tacrolimus improves renal function in de novo liver transplant recipients: a randomized controlled trial. Am J Transplant. 2012;12(1I):3008-3020. ${ }^{76}$ Copyright (C) 2013 The American Society of Transplantation and the American Society of Transplant Surgeons. Saliba F, De Simone P, Nevens F, et al; $\mathrm{H} 2304$ Study Group. Renal function at two years in liver transplant patients receiving everolimus: results of a randomized, multicenter study. Am J Transplant. 20 I3; 13(7): 1734-1745. ${ }^{77}$

Abbreviations: EVR, everolimus; TAC, tacrolimus; eGFR, estimated glomerular filtration rate. everolimus plus reduced tacrolimus. Furthermore, the benefit in eGFR was also evident using different formulas (Chronic Kidney Disease Epidemiology Collaboration, Nankivell, and Cockcroft-Gault). For the tacrolimus elimination group, the mean difference in GFR at month 24 versus that in the standard tacrolimus group was $10.4 \mathrm{~mL} / \mathrm{minute} / 1.73 \mathrm{~m}^{2}$; $97.5 \%$ confidence interval, $5.6-15.3 \mathrm{~mL} / \mathrm{minute} / 1.73 \mathrm{~m}^{2}$; $P=0.002$, intent-to-treat population). ${ }^{77}$

\section{Safety and tolerability}

Overall, everolimus showed a comparable safety profile to standard-of-care treatment in the largest clinical trial comparing everolimus plus reduced tacrolimus with standard-exposure tacrolimus in de novo liver transplant recipients (Figure 3). ${ }^{77}$ In clinical trials, specific events such as infections, hyperlipidemia, neutropenia, peripheral edema, stomatitis/mouth ulceration, arterial hypertension, anemia, leukopenia, thrombocytopenia, dry skin, eczema, and rash were more frequent in patients receiving an everolimus-based regimen. More patients randomized to everolimus discontinued study drug than in the control groups, mainly because of adverse events. ${ }^{74,77-79}$ The following sections summarize the key safety events reported from comparative trials of everolimus in liver transplant recipients.

\section{Urinary protein excretion}

mTOR inhibitor treatment in general is associated with a net increase in urinary protein excretion. ${ }^{85}$ In the H2304 study, in de novo liver transplant recipients, the incidence of proteinuria reported as an adverse event was low overall but was higher in the everolimus plus reduced tacrolimus group than in the standard tacrolimus group (3.7\% versus $0.8 \%$, respectively; $P=0.063$ ), and proteinuria was the leading cause of study drug discontinuation (eight versus one patient). However, the mean urine protein-to-creatinine ratio remained below the $500 \mathrm{mg}$ /day threshold. Of note, renal failure excluding proteinuria was more frequent in the standard tacrolimus group $(30.6 \%$ versus $21.2 \%$ in the everolimus group; $P=0.023) .{ }^{77}$ After CNI withdrawal in the PROTECT study, proteinuria was reported in $9.9 \%$ of everolimus-treated patients versus $2.0 \%$ of the patients in the CNI group $(P \leq 0.05)$. None of the cases of proteinuria were considered severe or serious. ${ }^{79}$ In the study of maintenance patients by De Simone et al, two patients discontinued everolimus because of proteinuria, which in both cases was suspected to be related to study medication. ${ }^{74}$ 


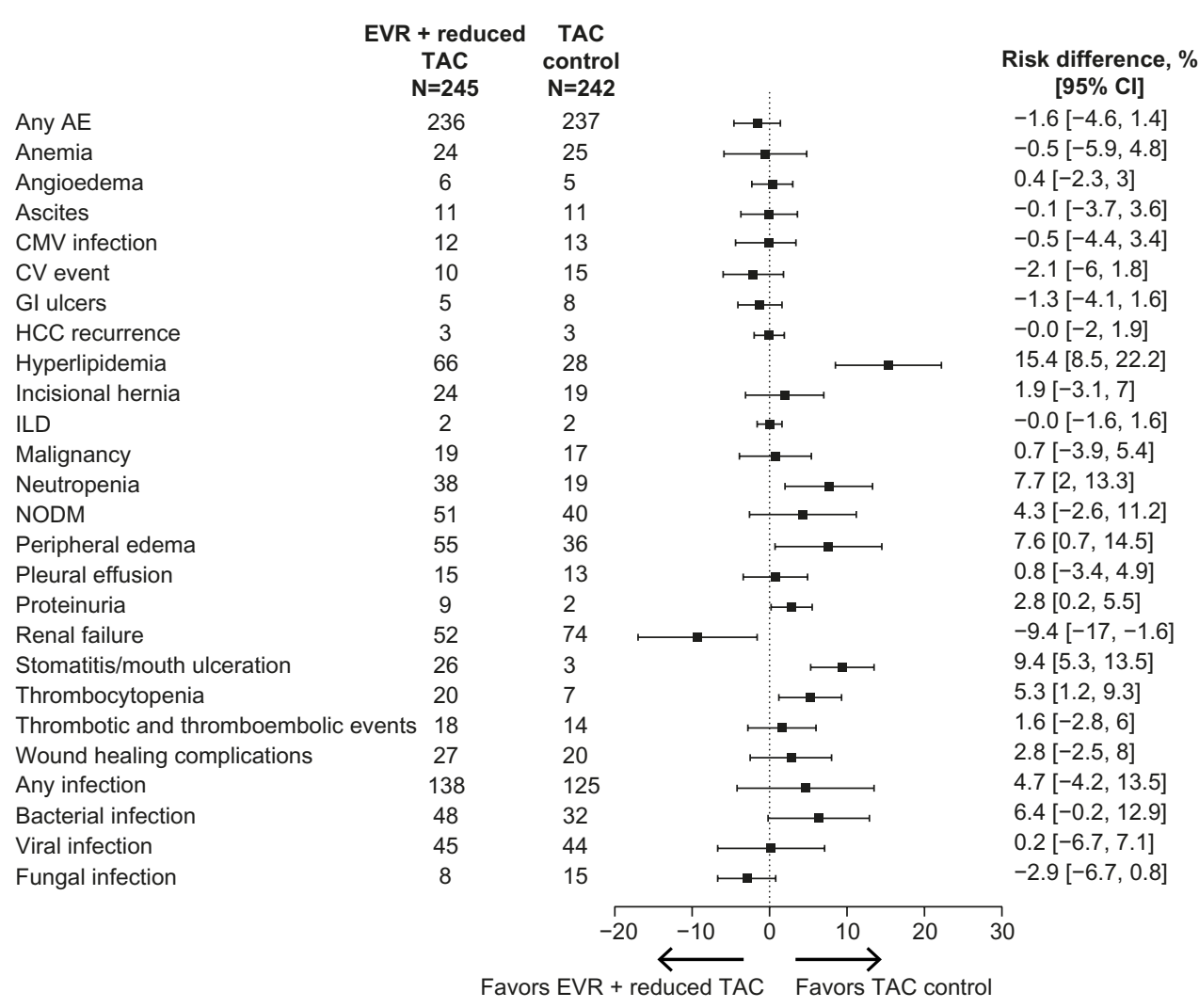

Figure $3 \mathrm{Key}$ adverse events with everolimus + reduced tacrolimus versus tacrolimus control in the $\mathrm{H} 2304$ study.

Note: Copyright (c) 2013 The American Society of Transplantation and the American Society of Transplant Surgeons. Saliba F, De Simone P, Nevens F, et al; H2304 Study Group. Renal function at two years in liver transplant patients receiving everolimus: results of a randomized, multicenter study. Am J Transplant. 20 I3; I3(7): I734-I745. ${ }^{77}$ Abbreviations: $\mathrm{AE}$, adverse event; $\mathrm{Cl}$, confidence interval; $\mathrm{CMV}$, cytomegalovirus; $\mathrm{CV}$, cardiovascular; EVR, everolimus; $\mathrm{Gl}$, gastrointestinal; $\mathrm{HCC}$, hepatocellular carcinoma; ILD, interstitial lung disease; NODM, new-onset diabetes mellitus; TAC, tacrolimus.

\section{Incisional hernia and wound healing complications}

A recent systematic review of randomized controlled trials in solid organ transplant recipients reported increased risk for poor wound healing and lymphoceles with immediate use of mTOR inhibitors posttransplant. ${ }^{86}$ Willems et al showed that loss of wound strength can be prevented by delaying postoperative administration of everolimus. ${ }^{87}$ In the study by Masetti et al, in which everolimus was initiated 10 days after transplantation, incisional hernias were reported more frequently in the everolimus group than with cyclosporine (46.1\% versus. $26.9 \%$ ), although the difference was not statistically significant $(P=0.16) .{ }^{78}$ Comparable rates of wound healing complications $(11.0 \%$ versus $8.3 \% ; P=0.36)$ and incisional hernias $(9.8 \%$ versus $7.9 \% ; P=0.52)$ with everolimus plus reduced tacrolimus versus standard tacrolimus in the H2304 study suggest that a delay in everolimus introduction can reduce the risk of wound healing complications. ${ }^{77}$ Similar results were seen in the PROTECT study, in which rates of incisional hernias (11.9\% versus 9.8\%) and wound healing complications $(2.0 \%$ versus $3.9 \%)$ were comparable in the everolimus and the CNI groups. ${ }^{79}$

\section{HAT}

Early HAT is a well-known complication after liver transplantation. In the H2304 study, 14 cases of HAT were reported during the prerandomization run-in phase. After randomization, one case of HAT was reported in the everolimus plus reduced tacrolimus group, after introduction of everolimus at 30 days posttransplant. This patient had previously experienced an episode of HAT during the run-in period, requiring re-anastomosis of the hepatic artery and stent placement. ${ }^{76}$ In the PROTECT study, and in the study by Masetti et al, no cases of HAT were reported in patients converted from a CNI-based to everolimus-based immunosuppression. ${ }^{78,79}$

\section{Lipid disorders and new-onset diabetes mellitus}

Dyslipidemia has been reported in $50 \%-60 \%$ of patients at 3-4 years after liver transplantation. ${ }^{32,88}$ In the H2304 study, hyperlipidemia as an adverse event was reported in a significantly higher proportion of patients in the everolimus group compared with in the tacrolimus control group (26.9\% versus $11.6 \% ; P<0.001) .{ }^{77}$ Similarly, in the PROTECT study, both hyperlipidemia and hypercholesterolemia were 
reported more frequently in the everolimus-treated patients than in CNI-treated patients (11.9\% versus $2.0 \%$ and $22.8 \%$ versus $10.8 \%$, respectively; both $P \leq 0.05) .{ }^{79}$ The relationship between increased dyslipidemia during mTOR inhibitor administration and cardiovascular outcomes has not been systematically evaluated, and thus the clinical effect of these adverse events is not fully understood. However, the proportion of patients receiving lipid-lowering treatment was similar with everolimus plus reduced tacrolimus or the standard-of-care tacrolimus treatment group $(23.3 \%$ versus $17.8 \% ; P=0.944)$ at 1 year posttransplant in the $\mathrm{H} 2304$ study. ${ }^{76}$ Furthermore, the incidence of cardiovascular events at month 24 did not differ between the two treatment groups (4.1\% versus $6.2 \% ; P=0.31) .{ }^{77}$

Among maintenance patients, hypercholesterolemia and hyperlipidemia were reported more frequently in the everolimus group compared with the CNI group (13.9\% versus $2.7 \%$ and $9.7 \%$ versus $2.7 \%$, respectively), and the difference was significant for hypercholesterolemia $(P=0.017) .^{74}$

NODM has been reported in $26 \%$ of liver transplant recipients, and the type of immunosuppressive therapy is one of the predictive factors for NODM after liver transplantation. ${ }^{89}$ NODM was reported in $20.8 \%$ of patients receiving everolimus plus reduced tacrolimus versus $16.5 \%$ of patients receiving standard-exposure tacrolimus at month 24 in the H2304 study $(P=0.25) .{ }^{77}$ Similarly, a comparable proportion of patients reported diabetes mellitus with everolimus and CNI (4.0\% versus $7.8 \%)$ in the PROTECT study. ${ }^{79}$

\section{Infections}

Infection is a well-recognized, frequent complication associated with immunosuppressive therapy. The incidence of infections varies between studies of everolimus in liver transplantation. In the H2304 study, the overall incidence was $56.3 \%$ in the everolimus group versus $51.7 \%$ in the tacrolimus control group, with no significant difference between groups. There was a trend toward more bacterial infections in the everolimus group (19.6\% versus $13.2 \%$ with standard tacrolimus; $P=0.067$ ). Cytomegalovirus infection as an adverse event was reported in $4.9 \%$ and $5.4 \%$ of patients in the everolimus and tacrolimus treatment groups, respectively $(P=0.84) .{ }^{77}$ In the study by Masetti et al, the incidence of major episodes of infections was identical in the everolimus and cyclosporine groups (46.1\%), but fungal infections were significantly more frequent with cyclosporine than everolimus (five cases versus one case; $P=0.011) .{ }^{78}$ Infections and infestations were more frequent under everolimus therapy than CNI therapy in the PROTECT study $(73.3 \%$ versus $59.8 \%$ ). Cytomegalovirus infection was reported in $7.9 \%$ of patients in the everolimus group compared with $10.8 \%$ patients in the CNI group. ${ }^{79}$ In maintenance patients, De Simone et al reported infections in $31.9 \%$ of patients in the everolimus group versus $21.9 \%$ of patients in the CNI group. ${ }^{74}$

\section{Peripheral edema}

Edema is a class effect observed with mTOR inhibitors. In the de novo setting (H2304 study), peripheral edema was reported more frequently in the everolimus plus reduced tacrolimus group versus the tacrolimus control group (22.4\% versus $14.9 \% ; P=0.036) .{ }^{77}$ Masetti et al reported inferior limb edema in five patients in the everolimus group versus none in the cyclosporine group $(P=0.16) .{ }^{78}$ In maintenance patients as well, higher incidence of peripheral edema was reported in everolimus-treated patients compared with in CNI-treated patients (5.6\% versus $1.4 \%)$, although the difference was not significant. ${ }^{74}$

\section{Interstitial lung disease}

Interstitial lung disease is a rare but potentially fatal event associated with mTOR inhibitors as a class. In the H2304 study of de novo liver transplant recipients, interstitial lung disease was reported in two patients $(0.8 \%)$ in both the everolimus plus reduced tacrolimus group and the standard tacrolimus group during the 24-month study period. ${ }^{77}$ In the CNI withdrawal setting (PROTECT study), one case of interstitial lung disease was reported in the everolimus group. ${ }^{79}$ In maintenance patients, one case of interstitial lung disease suspected to be related to study drug was reported in the everolimus group. ${ }^{74}$

\section{Stomatitis/mouth ulceration}

Stomatitis/mouth ulceration is one of the common adverse events that has been reported with mTOR inhibitor therapy. In de novo setting (H2304 study), the incidence rate of stomatitis was $10.6 \%$ in patients receiving everolimus compared with $1.2 \%$ in patients receiving standard tacrolimus $(P<0.001) .{ }^{77}$ Masetti et al reported aphthous-type mouth ulceration in two everolimus-treated patients, which resolved with dose reduction. ${ }^{78}$ In the maintenance setting, De Simone et al reported mouth ulceration in $26.4 \%$ of patients who were converted from a CNI-based regimen to everolimus with CNI reduction or discontinuation compared with none of the patients in the CNI continuation group $(P<0.010){ }^{74}$ 


\section{Special liver transplant populations $\mathrm{HCV}$ cirrhosis}

There is a lack of robust evidence regarding the ideal immunosuppressive regimen for $\mathrm{HCV}$-positive liver transplant recipients. However, although data are limited, everolimus may offer a benefit for posttransplant HCV-related fibrosis progression. In a subgroup of $\mathrm{HCV}$-positive transplant recipients in the H2304 study, fibrosis progression (defined as 1 or more stage on the Ishak/Knodell score $)^{90}$ occurred in fewer everolimus-treated patients compared with patients receiving standard tacrolimus (14/29 [48.3\%] versus $22 / 35$ [62.9\%]; $P=0.087$ ). ${ }^{91}$ In an another study conducted in 43 recurrent HCV-positive patients, Villamil et al reported fibrosis progression ( 1 or more Ishak/Knodell stage) in fewer patients in the everolimus group compared with in the CNI group (1/14 [7.1\%] versus 5/18 [27.8\%]; $P=0.060) .{ }^{92}$ Larger prospective studies in $\mathrm{HCV}$-positive liver transplant recipients are needed to confirm these preliminary findings.

\section{Pediatric liver transplantation}

Although there are few reports specifically relating to everolimus in pediatric liver transplant recipients, several studies in renal transplant recipients have shown it can be used safely in children ${ }^{93-98}$ Nielsen et al reported a single-center experience in which everolimus was given as rescue therapy in 18 pediatric liver transplant recipients, with a median follow-up of 13 months. The indications for use of everolimus were chronic graft dysfunction ( $\mathrm{N}=12), \mathrm{CNI}$ toxicity $(\mathrm{N}=3)$, hepatoblastoma $(\mathrm{N}=2)$, and recurrence of primary sclerosing cholangitis $(\mathrm{N}=1)$. Of the 12 patients treated with everolimus for chronic graft dysfunction, by the end of follow-up, four patients had normal liver function tests and six showed a partial improvement. An increase in GFR was noted in one of the three patients with suspected CNI nephrotoxicity, and patients with hepatoblastoma did not develop any metastasis. No new safety signals were observed. ${ }^{99}$ The ongoing H2305 study (NCT01598987) is the first prospective trial of everolimus (with reduced-exposure cyclosporine or tacrolimus) in pediatric liver transplant recipients. In addition to efficacy and general safety assessments, linear growth, sexual maturation, and hormonal gonadal axis are being closely monitored in this study to assess the potential effect of mTOR inhibition on development in children.

\section{Hepatocellular carcinoma}

Everolimus also acts as an antineoplastic agent, and therefore it may exert a beneficial effect in liver transplant recipients with HCC. In a retrospective analysis of 57 patients converted to an everolimus-based regimen mainly because of $\mathrm{HCC}$ recurrence $(53 \%)$ or development of de novo tumors $(33 \%)$, everolimus was well tolerated in patients with recurrent or de novo malignancies and provided a significant improvement in renal function along with a low rate of acute rejection. ${ }^{100}$ Prospective randomized studies are needed to further evaluate the role of everolimus immunosuppression in HCC.

\section{Living donor liver transplantation}

Transplantation of a partial liver from a healthy donor to a patient with end-stage liver disease can help address the ongoing problem of donor organ shortage. Studies reporting everolimus use in living-donor liver transplant recipients are scarce. Majeed et al used everolimus as a part of immunosuppressive protocol in patients with HCC undergoing living-donor liver transplantation. However, the focus of the study was to assess predictors of posttransplant survival. ${ }^{101}$ In living-donor liver transplant recipients, the efficacy and safety of everolimus plus reduced tacrolimus versus standard-exposure tacrolimus is being evaluated in a 24-month, phase 3, randomized, multicenter study (H2307; NCT01888432).

\section{Quality of life}

A systematic review showed that quality of life improves posttransplantation; however, compared with the general population, it still remains impaired. ${ }^{102}$ Adverse events associated with long-term exposure to immunosuppressive agents can contribute to this effect. Studies focusing on immunosuppression with everolimus in relation to quality of life and patient satisfaction/acceptability are limited. It will be interesting for future research to focus on the effect of immunosuppressive regimens on health-related quality of life in transplant recipients.

\section{Perspectives}

Before the approval of everolimus for use in liver transplantation, perceptions of mTOR inhibitors in this population were predominantly based on experience with sirolimus. Early studies with sirolimus (administered within 48 hours posttransplantation) reported high incidence of serious adverse events including HAT and wound healing complications, which may have been related to the use of loading doses and high maintenance doses (eg, a loading dose of $15 \mathrm{mg}$ followed by $5 \mathrm{mg} /$ day). ${ }^{59,103,104}$ Importantly, most of the HAT events in sirolimus-treated patients were reported within the first 30 days posttransplantation. As a consequence, sirolimus received a black box warning for use in liver transplantation. ${ }^{59}$ Although 


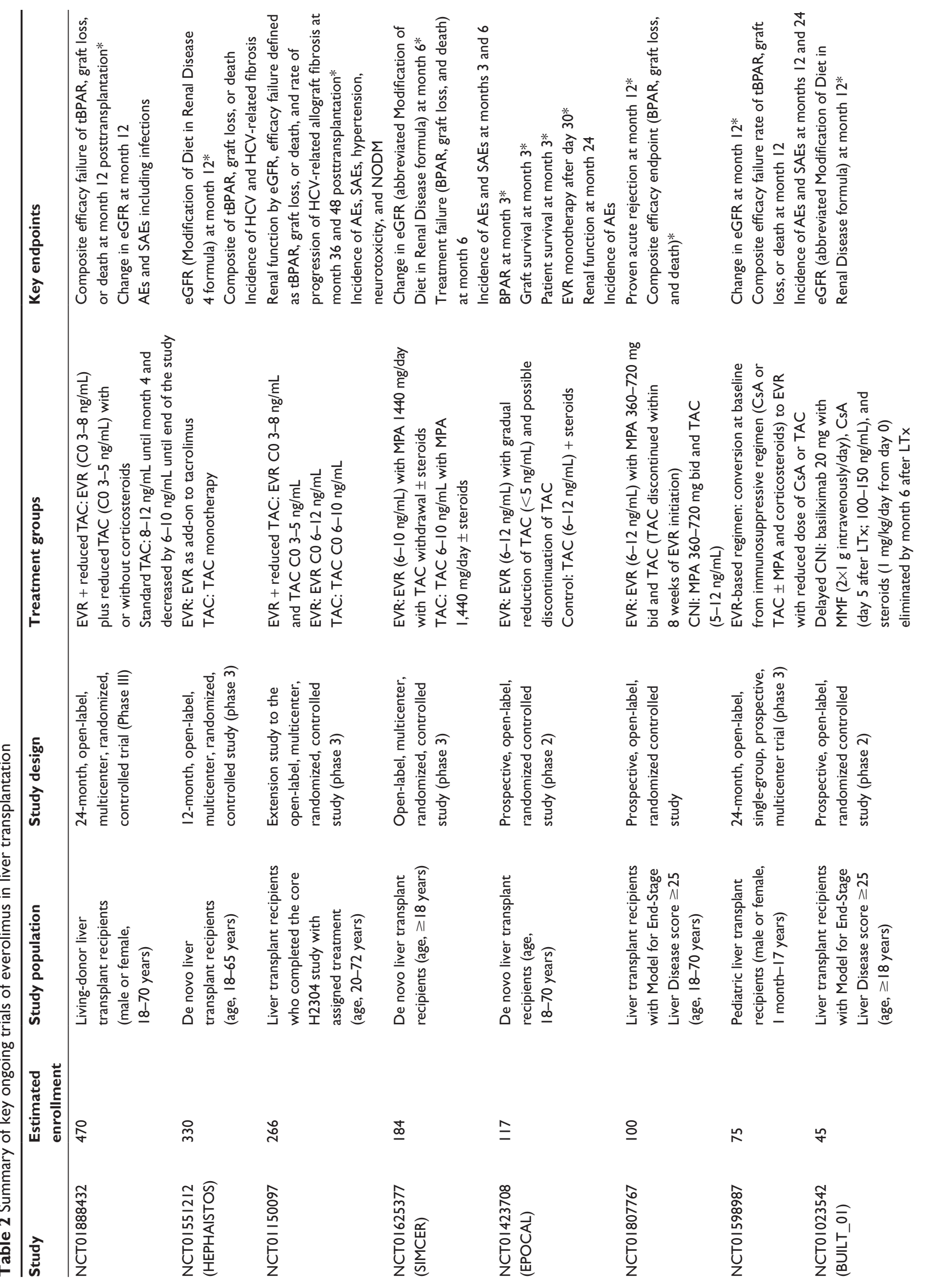







sirolimus is not approved in liver transplantation, recent studies using lower doses have shown an improved safety profile. ${ }^{105,106}$ Today's target ranges for everolimus (trough level [C0] 3-8 $\mathrm{ng} / \mathrm{mL}$ in combination with reduced tacrolimus) ${ }^{58}$ and the delay in administration of 30 days posttransplantation have reduced the risk for complications reported in early sirolimus trials. However, in almost all studies, the rate of study drug discontinuations was higher with everolimus than with CNI. This can be partly explained by the nature of open-label studies testing a new drug against an established drug. The opportunity to achieve CNI reduction with a related improvement in renal function with everolimus-based immunosuppression shown in the large randomized pivotal trial ${ }^{76-77}$ suggests a potential advantage for mTOR inhibitor immunosuppression when introduced at 30 days after liver transplantation.

In adult liver transplant recipients, everolimus has proven to be safe and effective over the course of 2 years' follow-up. ${ }^{77,79}$ Longer-term outcomes are yet to be investigated in prospectively conducted long-term follow-up studies. The extension phase of H2304 study (H2304E1; NCT01150097) will provide the longer-term renal function and safety outcomes in everolimus-treated patients. Tacrolimus elimination remains an attractive concept, but at present, a benefit has not been proven unequivocally, based on the difference between findings from the H2304 and PROTECT trials. It remains to be confirmed whether everolimus can help to address other unmet needs such as attenuating the progression of graft fibrosis and inhibiting HCC recurrence. Robust safety data will also be needed before everolimus can be used in pediatric patients and living donor transplant recipients. A summary of ongoing trials of everolimus in liver transplantation that will potentially address these unanswered questions is presented in Table 2.

Because everolimus has been shown to provide immunosuppressive efficacy with preservation of renal function preservation in both kidney and liver transplant recipients, its use in combined kidney and liver transplantation may be beneficial considering that a significant proportion of such patients develops renal dysfunction. ${ }^{107}$

\section{Conclusion, place in therapy}

Everolimus provides a new therapeutic option for liver transplant recipients, particularly with respect to posttransplant nephrotoxicity and other adverse events associated with longterm administration of CNIs. Clinical trials have shown that everolimus provides improved protection against renal dysfunction while maintaining immunosuppressive efficacy, particularly when introduced early after liver transplantation. Compared with standard-exposure tacrolimus, everolimus in combination with reduced-dose tacrolimus provides a significant improvement in renal function, sustained over 2 years. The available evidence supports the potentially beneficial effects of everolimus in HCC recurrence and HCVpositive and pediatric liver transplant recipients, although further data from prospective trials are awaited.

\section{Acknowledgment}

The authors thank Seema Dimri, Novartis Healthcare Pvt Ltd, India, for providing medical writing/editorial support. The first draft was prepared based on direction from the authors. All authors provided significant input and substantially contributed to the scientific contents. All authors approved the final draft submitted.

\section{Disclosure}

Rainer Ganschow and Jörg-Matthias Pollok have received travel grants from Novartis. Guido Junge is an employee of Novartis Pharma AG, Basel, Switzerland. Martin Jankofsky has nothing to disclose.

\section{References}

1. Starzl TE, Marchioro TL, Vonkaulla KN, Hermann G, Brittain RS, Waddell WR. Homotransplantation of the Liver in Humans. Surg Gynecol Obstet. 1963;117:659-676.

2. Starzl TE, Groth CG, Brettschneider L, et al. Orthotopic homotransplantation of the human liver. Ann Surg. 1968;168(3):392-415.

3. Zarrinpar A, Busuttil RW. Liver transplantation: past, present and future. Nat Rev Gastroenterol Hepatol. 2013;10(7):434-440.

4. Wiesner R, Edwards E, Freeman R, et al. Model for end-stage liver disease (MELD) and allocation of donor livers. Gastroenterology. 2003;124(1):91-96.

5. Mazzaferro V, Regalia E, Doci R, et al. Liver transplantation for the treatment of small hepatocellular carcinomas in patients with cirrhosis. N Engl J Med. 1996;334(11):693-699.

6. Shetty K, Timmins K, Brensinger C, et al. Liver transplantation for hepatocellular carcinoma validation of present selection criteria in predicting outcome. Liver Transpl. 2004;10(7):911-918.

7. Bismuth H, Houssin D. Reduced-sized orthotopic liver graft in hepatic transplantation in children. Surgery. 1984;95(3):367-370.

8. PichlmayrR, Ringe B, Gubernatis G, Hauss J, Bunzendahl H. Transplantation einer Spenderleber auf zwei Empfänger (Splitting-Transplantation) - eine neue Methode in der Weiterentwicklung der Lebersegmenttransplantation. Langenbecks Arch Chir. 198373(2):127-130. German.

9. Raia S, Nery JR, Mies S. Liver transplantation from live donors. Lancet. 1989;2(8661):497.

10. Strong RW, Lynch SV, Ong TH, Matsunami H, Koido Y, Balderson GA. Successful liver transplantation from a living donor to her son. N Engl J Med. 1990;322(21):1505-1507.

11. Charlton MR, Burns JM, Pedersen RA, Watt KD, Heimbach JK, Dierkhising RA. Frequency and outcomes of liver transplantation for nonalcoholic steatohepatitis in the United States. Gastroenterology. 2011;141(4):1249-1253.

12. Gordon RD, Shaw BW Jr, Iwatsuki S, Esquivel CO, Starzl TE. Indications for liver transplantation in the cyclosporine era. Surg Clin North Am. 1986;66(3):541-556.

13. Starzl TE, Demetris AJ, Van Thiel D. Liver transplantation (2). NEngl J Med. 1989;321(16):1092-1099. 
14. Moreno R, Berenguer M. Post-liver transplantation medical complications. Ann Hepatol. 2006;5(2):77-85.

15. Romero FA, Razonable RR. Infections in liver transplant recipients. World J Hepatol. 2011;3(4):83-92.

16. Berenguer M, Ferrell L, Watson J, et al. HCV-related fibrosis progression following liver transplantation: increase in recent years. J Hepatol. 2000;32(4):673-684.

17. Crespo G, Marino Z. Non-invasive diagnosis of liver fibrosis in the transplant setting. Digestive Liver Dis Suppl. 2011;5(1):23-25.

18. Welker MW, Bechstein WO, Zeuzem S, Trojan J. Recurrent hepatocellular carcinoma after liver transplantation - an emerging clinical challenge. Transpl Int. 2013;26(2):109-118.

19. Felga G, Evangelista AS, Salvalaggio PR, et al. Hepatocellular carcinoma recurrence among liver transplant recipients within the Milan criteria. Transplant Proc. 2012;44(8):2459-2461.

20. Pérez-Saborido B, de los Galanes SJ, Menéu-Díaz JC, et al. Tumor recurrence after liver transplantation for hepatocellular carcinoma: recurrence pathway and prognostic factors. Transplant Proc. 2007;39(7):2304-2307.

21. El-Masry M, Puig CA, Saab S. Recurrence of non-viral liver disease after orthotopic liver transplantation. Liver Int. 2011;31(3): 291-302.

22. Gonwa TA, Mai ML, Melton LB, et al. End-stage renal disease (ESRD) after orthotopic liver transplantation (OLTX) using calcineurin-based immunotherapy: risk of development and treatment. Transplantation. 2001;72(12):1934-1939.

23. Ojo AO, Held PJ, Port FK, et al. Chronic renal failure after transplantation of a nonrenal organ. $N$ Engl J Med. 2003;349(10): 931-940

24. Hauben M. Cyclosporine neurotoxicity. Pharmacotherapy. 1996;16(4): 576-583.

25. Gijtenbeek JM, van den Bent MJ, Vecht CJ. Cyclosporine neurotoxicity: a review. J Neurol. 1999;246(5):339-346.

26. Bechstein WO. Neurotoxicity of calcineurin inhibitors: impact and clinical management. Transpl Int. 20013(5):313-326.

27. Guba M, Graeb C, Jauch KW, Geissler EK. Pro- and anti-cancer effects of immunosuppressive agents used in organ transplantation. Transplantation. 2004;77(12):1777-1782.

28. Tjon AS, Sint Nicolaas J, Kwekkeboom J, et al. Increased incidence of early de novo cancer in liver graft recipients treated with cyclosporine: an association with $\mathrm{C} 2$ monitoring and recipient age. Liver Transpl. 2010;16(7):837-846

29. Wimmer CD, Angele MK, Schwarz B, et al. Impact of cyclosporine versus tacrolimus on the incidence of de novo malignancy following liver transplantation: a single center experience with 609 patients. Transpl Int. 2013;26(10):999-1006.

30. Subramanian S, Trence DL. Immunosuppressive agents: effects on glucose and lipid metabolism. Endocrinol Metab Clin North Am. 2007;36(4):891-905.

31. Vincenti F, Friman S, Scheuermann E, et al; DIRECT (Diabetes Incidence after Renal Transplantation: Neoral C Monitoring Versus Tacrolimus) Investigators. Results of an international, randomized trial comparing glucose metabolism disorders and outcome with cyclosporine versus tacrolimus. Am J Transplant. 2007;7(6):1506-1514.

32. Bianchi G, Marchesini G, Marzocchi R, Pinna AD, Zoli M. Metabolic syndrome in liver transplantation: relation to etiology and immunosuppression. Liver Transpl. 2008;14(11):1648-1654.

33. Pham PT, Pham PC, Wilkinson AH. Management of renal dysfunction in the liver transplant recipient. Curr Opin Organ Transplant. 2009;14(3):231-239.

34. Sharma P, Welch K, Eikstadt R, Marrero JA, Fontana RJ, Lok AS. Renal outcomes after liver transplantation in the model for end-stage liver disease era. Liver Transpl. 2009;15(9):1142-1148.

35. Campbell KM, Bucuvalas JC. Renal function in the long term after pediatric liver transplantation: is there a need for protocol kidney biopsies? Curr Opin Organ Transplant. 2010;15(5):608-613.
36. Viner RM, Forton JT, Cole TJ, Clark IH, Noble-Jamieson G, Barnes ND. Growth of long-term survivors of liver transplantation. Arch Dis Child. 1999;80(3):235-240.

37. Bartosh SM, Thomas SE, Sutton MM, Brady LM, Whitington PF. Linear growth after pediatric liver transplantation. J Pediatr. 1999;135(5):624-631.

38. Campbell KM, Yazigi N, Ryckman FC, et al. High prevalence of renal dysfunction in long-term survivors after pediatric liver transplantation. J Pediatr. 2006;148(4):475-480.

39. Vivarelli M, Cucchetti A, La Barba G, et al. Liver transplantation for hepatocellular carcinoma under calcineurin inhibitors: reassessment of risk factors for tumor recurrence. Ann Surg. 2008;248(5): $857-862$.

40. Vivarelli M, Cucchetti A, Piscaglia F, et al. Analysis of risk factors for tumor recurrence after liver transplantation for hepatocellular carcinoma: key role of immunosuppression. Liver Transpl. 2005;11(5): 497-503.

41. Soliman T, Hetz H, Burghuber C, et al. Short-term induction therapy with anti-thymocyte globulin and delayed use of calcineurin inhibitors in orthotopic liver transplantation. Liver Transpl. 2007;13(7): 1039-1044.

42. Liu CL, Fan ST, Lo CM, et al. Interleukin-2 receptor antibody (basiliximab) for immunosuppressive induction therapy after liver transplantation: a protocol with early elimination of steroids and reduction of tacrolimus dosage. Liver Transpl. 2004;10(6):728-733.

43. Ramirez CB, Doria C, di Francesco F, Iaria M, Kang Y, Marino IR. Anti-IL2 induction in liver transplantation with $93 \%$ rejection-free patient and graft survival at 18 months. J Surg Res. 2007;138(2): 198-204.

44. Turner AP, Knechtle SJ. Induction immunosuppression in liver transplantation: a review. Transpl Int. 2013;26(7):673-683.

45. Gras JM, Gerkens S, Beguin C, et al. Steroid-free, tacrolimusbasiliximab immunosuppression in pediatric liver transplantation: clinical and pharmacoeconomic study in 50 children. Liver Transpl. 2008;14(4):469-477.

46. Spada M, Petz W, Bertani A, et al. Randomized trial of basiliximab induction versus steroid therapy in pediatric liver allograft recipients under tacrolimus immunosuppression. Am J Transplant. 2006;6(8): 1913-1921.

47. Ganschow R, Grabhorn E, Schulz A, Von Hugo A, Rogiers X, Burdelski M. Long-term results of basiliximab induction immunosuppression in pediatric liver transplant recipients. Pediatr Transplant. 2005;9(6):741-745.

48. Ganschow R, Broering DC, Stuerenburg I, Rogiers X, Hellwege HH, Burdelski M. First experience with basiliximab in pediatric liver graft recipients. Pediatr Transplant. 2001;5(5):353-358.

49. Wiesner RH, Fung JJ. Present state of immunosuppressive therapy in liver transplant recipients. Liver Transpl. 2011;17 Suppl 3: S1-S9.

50. Kim WR, Smith JM, Skeans MA, et al. OPTN/SRTR 2012 Annual Data Report: liver. Am J Transplant. 2014;14 Suppl 1:69-96.

51. Neoral ${ }^{\circledR}$ (cyclosporine) [package insert]. East Hanover, NJ: Novartis Pharmaceuticals Corporation; 2013.

52. $\operatorname{Prograf}^{\circledR}$ (tacrolimus) [package insert]. Northbrook, IL: Astellas Pharma US Inc.; 2013.

53. CellCept ${ }^{\mathbb{\mathbb { }}}$ (mycophenolate) [package insert]. South San Francisco, CA: Genentech USA Inc.; 2013.

54. Sedrani R, Cottens S, Kallen J, Schuler W. Chemical modification of rapamycin: the discovery of SDZ RAD. Transplant Proc. 1998;30(5): 2192-2194.

55. Schuler W, Sedrani R, Cottens S, et al. SDZ RAD, a new rapamycin derivative: pharmacological properties in vitro and in vivo. Transplantation. 1997;64(1):36-42.

56. Kirchner GI, Meier-Wiedenbach I, Manns MP. Clinical pharmacokinetics of everolimus. Clin Pharmacokinet. 2004;43(2):83-95.

57. Salvadori M, Bertoni E. Long-term outcome of everolimus treatment in transplant patients. Transpl Res Risk Manag. 2011;3:77-90. 
58. Zortress ${ }^{\circledR}$ (everolimus) [package insert]. East Hanover, NJ: Novartis Pharmaceuticals Corporation; 2013.

59. Rapamune ${ }^{\circledR}$ (sirolimus) [package insert]. New York, NY: Pfizer, Inc.; 2011.

60. Halloran PF. Immunosuppressive drugs for kidney transplantation. N Engl J Med. 2004;351(26):2715-2729.

61. Wullschleger S, Loewith R, Hall MN. TOR signaling in growth and metabolism. Cell. 2006;124(3):471-484.

62. Nashan B. Review of the proliferation inhibitor everolimus. Expert Opin Investig Drugs. 2002;11(12):1845-1857.

63. Guba M, von Breitenbuch P, Steinbauer M, et al. Rapamycin inhibits primary and metastatic tumor growth by antiangiogenesis: involvement of vascular endothelial growth factor. Nat Med. 2002;8(2): $128-135$.

64. Contreras AG, Dormond O, Edelbauer M, et al. mTOR-understanding the clinical effects. Transplant Proc. 2008;40(Suppl 10):S9-S12.

65. Cruzado JM. Nonimmunosuppressive effects of mammalian target of rapamycin inhibitors. Transplant Rev (Orlando). 2008;22(1):73-81.

66. Fasolo A, Sessa C. Targeting mTOR pathways in human malignancies. Curr Pharm Des. 2012;18(19):2766-2777.

67. Kawahara T, Asthana S, Kneteman NM. m-TOR inhibitors: what role in liver transplantation? J Hepatol. 2011;55(6):1441-1451.

68. Kovarik JM, Beyer D, Bizot MN, Jiang Q, Shenouda M, Schmouder RL. Effect of multiple-dose erythromycin on everolimus pharmacokinetics. Eur J Clin Pharmacol. 2005;61(1):35-38.

69. Kovarik JM, Beyer D, Bizot MN, Jiang Q, Allison MJ, Schmouder RL. Pharmacokinetic interaction between verapamil and everolimus in healthy subjects. Br J Clin Pharmacol. 2005;60(4):434-437.

70. Kovarik JM, Beyer D, Bizot MN, Jiang Q, Shenouda M, Schmouder RL. Blood concentrations of everolimus are markedly increased by ketoconazole. J Clin Pharmacol. 2005;45(5):514-518.

71. Kovarik JM, Beyer D, Schmouder RL. Everolimus drug interactions: application of a classification system for clinical decision making. Biopharm Drug Dispos. 2006;27(9):421-426.

72. Schuurman HJ, Cottens S, Fuchs S, et al. SDZ RAD, a new rapamycin derivative: synergism with cyclosporine. Transplantation. 1997;64(1): 32-35.

73. Kovarik JM, Curtis JJ, Hricik DE, Pescovitz MD, Scantlebury V, Vasquez A. Differential pharmacokinetic interaction of tacrolimus and cyclosporine on everolimus. Transplant Proc. 2006;38(10): 3456-3458.

74. De Simone P, Metselaar HJ, Fischer L, et al. Conversion from a calcineurin inhibitor to everolimus therapy in maintenance liver transplant recipients: a prospective, randomized, multicenter trial. Liver Transpl. 2009;15(10):1262-1269.

75. De Simone P, Carrai P, Precisi A, et al. Conversion to everolimus monotherapy in maintenance liver transplantation: feasibility, safety, and impact on renal function. Transpl Int. 2009;22(3):279-286.

76. De Simone P, Nevens F, De Carlis L, et al; H2304 Study Group. Everolimus with reduced tacrolimus improves renal function in de novo liver transplant recipients: a randomized controlled trial. $\mathrm{Am} \mathrm{J}$ Transplant. 2012;12(11):3008-3020.

77. Saliba F, De Simone P, Nevens F, et al; H2304 Study Group. Renal function at two years in liver transplant patients receiving everolimus: results of a randomized, multicenter study. Am JTransplant. 2013;13(7):1734-1745.

78. Masetti M, Montalti R, Rompianesi G, et al. Early withdrawal of calcineurin inhibitors and everolimus monotherapy in de novo liver transplant recipients preserves renal function. Am J Transplant. 2010;10(10):2252-2262.

79. Fischer L, Klempnauer J, Beckebaum S, et al. A randomized, controlled study to assess the conversion from calcineurin-inhibitors to everolimus after liver transplantation - PROTECT. Am J Transplant. 2012;12(7): $1855-1865$.

80. Levy G, Schmidli H, Punch J, et al. Safety, tolerability, and efficacy of everolimus in de novo liver transplant recipients: 12- and 36-month results. Liver Transpl. 2006;12(11):1640-1648.
81. Levy GA, Grant D, Paradis K, Campestrini J, Smith T, Kovarik JM. Pharmacokinetics and tolerability of 40-0-[2-hydroxyethyl] rapamycin in de novo liver transplant recipients. Transplantation. 2001;71(1):160-163.

82. Saliba F, Dharancy S, Lorho R, et al. Conversion to everolimus in maintenance liver transplant patients: a multicenter, retrospective analysis. Liver Transpl. 2011;17(8):905-913.

83. Levey AS, Bosch JP, Lewis JB, et al. A more accurate method to estimate glomerular filtration rate from serum creatinine: a new prediction equation. Modification of Diet in Renal Disease Study Group. Ann Intern Med. 1999;130(6):461-470.

84. Gonwa TA, Jennings L, Mai ML, et al. Estimation of glomerular filtration rates before and after orthotopic liver transplantation: evaluation of current equations. Liver Transpl. 2004;10(2):301-309.

85. Letavernier E, Legendre C. mToR inhibitors-induced proteinuria: mechanisms, significance, and management. Transplant Rev (Orlando). 2008;22(2): 125-130.

86. Pengel LH, Liu LQ, Morris PJ. Do wound complications or lymphoceles occur more often in solid organ transplant recipients on mTOR inhibitors? A systematic review of randomized controlled trials. Transpl Int. 2011;24(12):1216-1230.

87. Willems MC, Hendriks T, de Man BM, Lomme RM, van der Vliet JA. Everolimus-induced loss of wound strength can be prevented by a short postoperative delay in its administration. Wound Repair Regen. 2011;19(6):680-686.

88. Neal DA, Tom BD, Luan J, et al. Is there disparity between risk and incidence of cardiovascular disease after liver transplant? Transplantation. 2004;77(1):93-99.

89. Kuo HT, Sampaio MS, Ye X, Reddy P, Martin P, Bunnapradist S. Risk factors for new-onset diabetes mellitus in adult liver transplant recipients, an analysis of the Organ Procurement and Transplant Network/United Network for Organ Sharing database. Transplantation. 2010;89(9):1134-1140.

90. Ishak K, Baptista A, Bianchi L, et al. Histological grading and staging of chronic hepatitis. J Hepatol. 1995;22(6):696-699.

91. Saliba F, Brown RS, Metselaar HJ, et al. Everolimus based immunosuppression in hepatitis $\mathrm{C}$ virus positive de novo liver transplant recipients: 24-month results from a randomized controlled trial [abstract]. Liver Transpl. 2013;19(Suppl 1):S100.

92. Villamil FG, Gadano AC, Zingale F, et al. Fibrosis progression in maintenance liver transplant patients with hepatitis $\mathrm{C}$ recurrence: a randomised study of everolimus vs calcineurin inhibitors. Liver Int. Epub 2013 Dec 15.

93. Ganschow R, Pape L, Sturm E, et al. Growing experience with mTOR inhibitors in pediatric solid organ transplantation. Pediatr Transplant. 2013;17(7):694-706.

94. Van Damme-Lombaerts R, Webb NA, Hoyer PF, et al; Everolimus Study Group. Single-dose pharmacokinetics and tolerability of everolimus in stable pediatric renal transplant patients. Pediatr Transplant. 2002;6(2):147-152.

95. Hoyer PF, Ettenger R, Kovarik JM, et al; Everolimus Pediatric Study Group. Everolimus in pediatric de nova renal transplant patients. Transplantation. 2003;75(12):2082-2085.

96. Kovarik JM, Noe A, Berthier S, et al. Clinical development of an everolimus pediatric formulation: relative bioavailability, food effect, and steadystate pharmacokinetics. J Clin Pharmacol. 2003;43(2): 141-147.

97. Pape L, Lehner F, Blume C, Ahlenstiel T. Pediatric kidney transplantation followed by de novo therapy with everolimus, low-dose cyclosporine A, and steroid elimination: 3-year data. Transplantation. 2011;92(6):658-662.

98. Pape L, Ahlenstiel T, Ehrich JH, Offner G. Reversal of loss of glomerular filtration rate in children with transplant nephropathy after switch to everolimus and low-dose cyclosporine A. Pediatr Transplant. 2007;11(3):291-295.

99. Nielsen D, Briem-Richter A, Sornsakrin M, Fischer L, Nashan B, Ganschow R. The use of everolimus in pediatric liver transplant recipients: first experience in a single center. Pediatr Transplant. 2011;15(5):510-514. 
100. Alegre C, Jiménez C, Manrique A, et al. Everolimus monotherapy or combined therapy in liver transplantation: indications and results. Transplant Proc. 2013;45(5):1971-1974.

101. Majeed TA, Wai CT, Rajekar H, et al. Experience of the transplant team is an important factor for posttransplant survival in patients with hepatocellular carcinoma undergoing living-donor liver transplantation. Transplant Proc. 2008;40(8):2507-2509.

102. Tome S, Wells JT, Said A, Lucey MR. Quality of life after liver transplantation. A systematic review. J Hepatol. 2008;48(4): 567-577.

103. Wiesner R, Klintmalm G, McDiarmid S, Rapamune Liver Transplant Study Group. Sirolimus immunotherapy results in reduced roles of acute rejection in de novo orthotopic liver transplant recipients. $A m \mathrm{~J}$ Transpl. 2002;2:464.
104. Asrani SK, Wiesner RH, Trotter JF, et al. De novo sirolimus and reduced-dose tacrolimus versus standard-dose tacrolimus after liver transplantation: the 2000-2003 phase II prospective randomized trial. Am J Transplant. 2014;14(2):356-366.

105. Chinnakotla S, Davis GL, Vasani S, et al. Impact of sirolimus on the recurrence of hepatocellular carcinoma after liver transplantation. Liver Transpl. 2009;15(12):1834-1842.

106. McKenna GJ, Trotter JF, Klintmalm E, et al. Limiting hepatitis C virus progression in liver transplant recipients using sirolimus-based immunosuppression. Am J Transplant. 2011;11(11):2379-2387.

107. Chava SP, Singh B, Stangou A, et al. Simultaneous combined liver and kidney transplantation: a single center experience. Clin Transplant. 2010;24(3):E62-E68.

\section{Publish your work in this journal}

Clinical and Experimental Gastroenterology is an international, peerreviewed, open access journal, publishing all aspects of gastroenterology in the clinic and laboratory, including: Pathology, pathophysiology of gastrointestinal disease; Investigation and treatment of gastointestinal disease; Pharmacology of drugs used in the alimentary tract;
Immunology/genetics/genomics related to gastrointestinal disease. This journal is indexed on CAS. The manuscript management system is completely online and includes a very quick and fair peer-review system. Visit http://www.dovepress.com/testimonials.php to read real quotes from published authors.

Submit your manuscript here: http://www.dovepress.com/clinical-and-experimental-gastroenterology-journal 